\title{
Environment Monitoring of an Enclosed Place Like Underground Mines with ANSYS Software and Sensors Based Technology
}

\author{
PARTHA SARATHI DAS ${ }^{* 1}$, TANMOY MAITY ${ }^{2}$ and YOGENDRA SINGH DOHARE ${ }^{3}$ \\ 'Department of Electrical Engineering, Durgapur Institute of Advanced \\ Technology and Management,, Durgapur - 713212, India. \\ ${ }^{2}$ Department of Mining Machinery Engineering, Indian School of Mines,Dhanbad - 826004, india. \\ ${ }^{3}$ Department of Electrical Engineering, Indian School of Mines,Dhanbad - 826004, India.
}

http://dx.doi.org/10.12944/CWE.9.3.37

(Received: July 26, 2014; Accepted: August 16, 2014)

\begin{abstract}
This paper deals with the issue of safety inside underground mines. The safety system designed based on wireless sensor network. The position of the different sensors inside underground mines is set by using analysis with ANSYS software. The safety system modeling in this paper is cost effective, energy saver, consistent, uninterrupted. This system performs automatic monitoring of different useful parameters inside underground mines required for the safety of the mine personals. Transmission of data to the base station is done by using Zigbee technology. This total scheme concept may be implemented with necessary modification in multiplex, hospital, shopping mall etc.
\end{abstract}

Key words: Wireless sensor network, Hospital, Shopping mall, Safety, ANSYS, Zigbee.

\section{INTRODUCTION}

Mine industries have an extensive diversity of process connecting with working with chemicals. The state of these chemicals contributes to threat like explosion, problems of human health when these chemicals are beyond their tolerance limit. Air pollution is also the major cause for many premature deaths ${ }^{[1]}$. Inside underground mines different gases are present there. Certain huge amount of toxic risky chemicals which are always present in underground mines, it is necessary to control these chemicals. It is very much essential to monitor different properties of these chemicals time to time. The base station should have the knowledge of distribution of these gases inside underground mines for future assessment. There are ever-increasing demands on the global mining industry to improve underground safety and still maintain an improvement in overall operational efficiency ${ }^{[2]}$. The possibility of accidents due to chemicals inside underground mines is a very serious anxiety, for the personals working within the premises of underground mines. Major disasters inside underground mines causes losses of lives of mine personals, bad injuries like permanent damage of organ, pollution of surrounding environment etc. It has also many times long term impact on drinking water, air, nearby paddy field, losses of public property etc. Mine accidents and injuries are complex and generally characterized by several factors starting from personal to technical, and technical to social characteristics ${ }^{[3]}$. From socio-economic point of view prevention of disasters is one of great concern. Many reasons behind these disasters are human error ,negligence, failure of safety system ,unreliability of information collection etc. Forecasting of an impending disaster alarm system should be faithful. Early detection of trace amounts of toxic gases in an open environment is vital for any successful attempt to contain subsequent damage ${ }^{[4]}$.An unwanted happening can instigate a sequence of unrestrained fact for instance huge devastation like 
fires, roof falls and explosions. The leakage and diffusion accident of inflammable and explosive toxic gas has become a serious problem in the field of environment and security ${ }^{[5]}$.Analysis, constant monitoring of different gas mixtures, temperature of the mixtures at each point in the working region are an essential requirement to avoid any type of disaster due to fire. When a gas present in the environment of underground mines having flash point below the surrounding temperature it may release a adequate amount of vapors to give rise to flammable mixtures with air. Discharge of energy in fast and uncontrolled way finally leads to explosion. A fire disaster is also a source of potentially hazardous gases ${ }^{[6]}$. To monitor different parameters like temperature, pressure, vibration, concentration of flammable and poisonous gases, different types of sensors are required. An effective communication system is required to transmit the information regarding the magnitude of the above mentioned parameters to the base station. Sensing of flammable and poisonous gases inside underground mines is vital. Toxic gas detection is a common issue of interest in domestic as well as industrial environments ${ }^{[7]}$. The objective of safety machinery is to maintain the prospective

Hazards for the personals working in underground mines and the surroundings in side underground mines as low as possible by the application of latest advanced technology. Wireless sensor network (WSN) plays an important task for communication ie data transmission inside underground mines. Wireless sensor networks (WSNs) have been becoming increasingly essential in recent years because of their ability to manage real-time situational information for various novel services ${ }^{[8]}$. Uninterrupted monitoring of the adjacent working environment can be monitored successfully, competently, precisely by the use of wireless sensor network. In Wireless sensor networks (WSN's), various tiny wireless sensor nodes or motes collect the data from the surrounding areas, where they are deployed and forward the same towards the gateway ${ }^{[9]}$. Disaster management system required measurement of different parameters like temperature, concentration, velocity of different harmful gases inside underground mines. Accurate Information to exact personal in exact instant is vital to prevent disaster. A reliable underground communication network in mines will not only facilitate the day to day operations but will also help save many lives. However, designing reliable and robust underground network has always been a challenge due to the special nature of mines ${ }^{[10]}$ .Zigbee technology for transmitting data is very useful in this regard. ZigBee is a communication standard which is considered to be suitable for wireless sensor networks ${ }^{[1]}$.

\section{Modeling of Wireless sensor network system}

A wired communication system inside underground mines is not effective, efficient, economic and reliable. Due to unexpected roof fall at any moment the entire communication system of the total network may collapse. Effective communication is critical to the success of response and rescue operations; however, unreliable operation of communication systems in high-stress environments is a significant obstacle to achieving this ${ }^{[12]}$. To improve security, protection and productivity in underground mines, a consistent communication system must be established between personnel, working in the premises of underground mine, and the control room. A wireless communication system is must for the safety point of view of the personal working inside the underground mines. It is fast , accurate , flexible, reliable. Wireless sensor network technology is used in our work.

The key issue of researches on wireless sensor networks is to balance the energy costs across the whole network and to enhance the robustness in order to extend the survival time of the whole sensor network ${ }^{[13]}$.A wireless sensor network(WSNs) has some major characteristics; the ability to monitor physical and environmental conditions; and the ability to provide efficient, reliable communications.

A wireless sensor network(WSNs) are usually low data rate, low latency and self-organizing is a arbitrarily spaced collection of nodes. A wireless sensor network consist of small devices, called sensor nodes that are equipped with sensors to monitor the physical and environmental conditions such as pressure, temperature, humidity, motion, speed etc ${ }^{[14]}$ Wireless sensor networks utilize large numbers of wireless sensor nodes to collect information from their sensing terrain ${ }^{[15]}$. The placement of different sensors inside the underground mines is based 
on ANSYS analysis. Different alarm sound will be there for different threats. For ex. if methane gas exceeds its tolerance level a beep sound will be there. One of the most important actual problems is to prevent the explosions due to the combustible gases accumulations and intoxications due to the toxic gases accumulations and/or leakages ${ }^{[16]}$.

The system has real-time continuous monitor the underground environment by using a

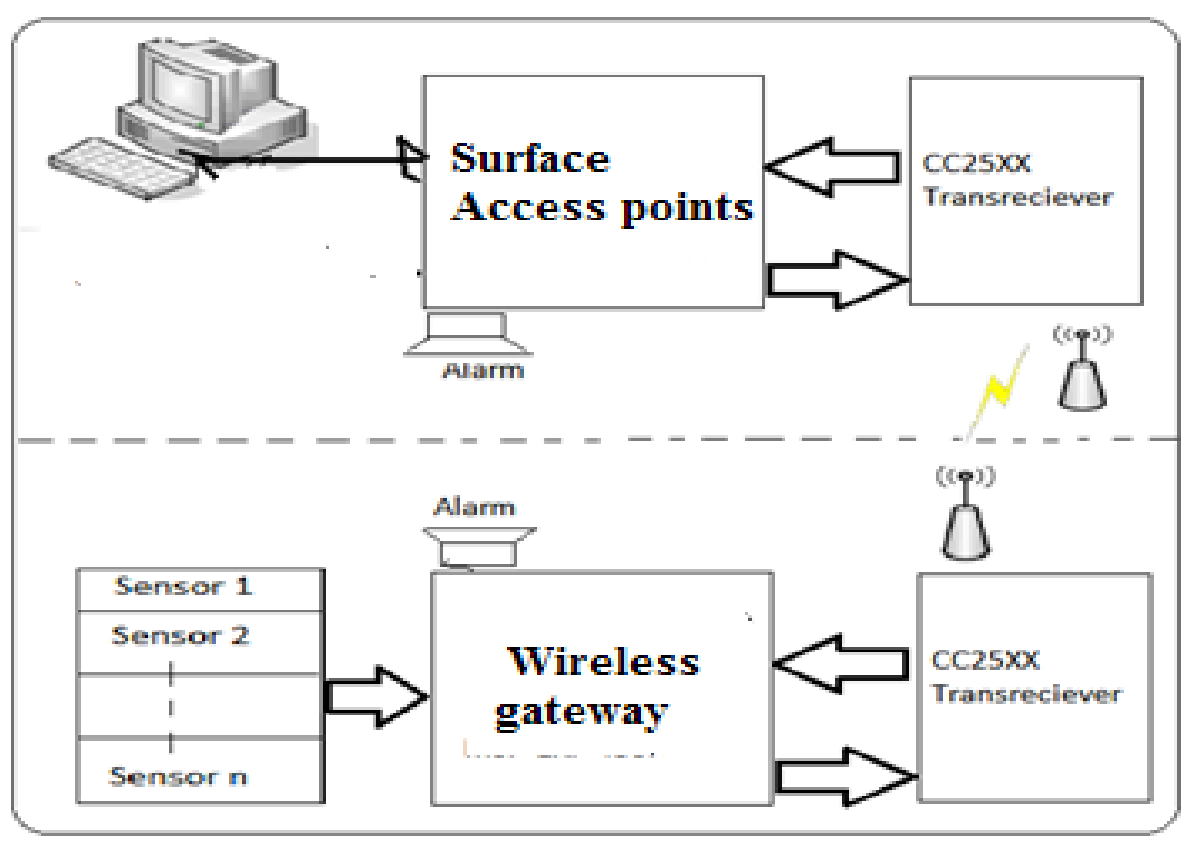

Fig. 1: Overall block diagram for the proposed system

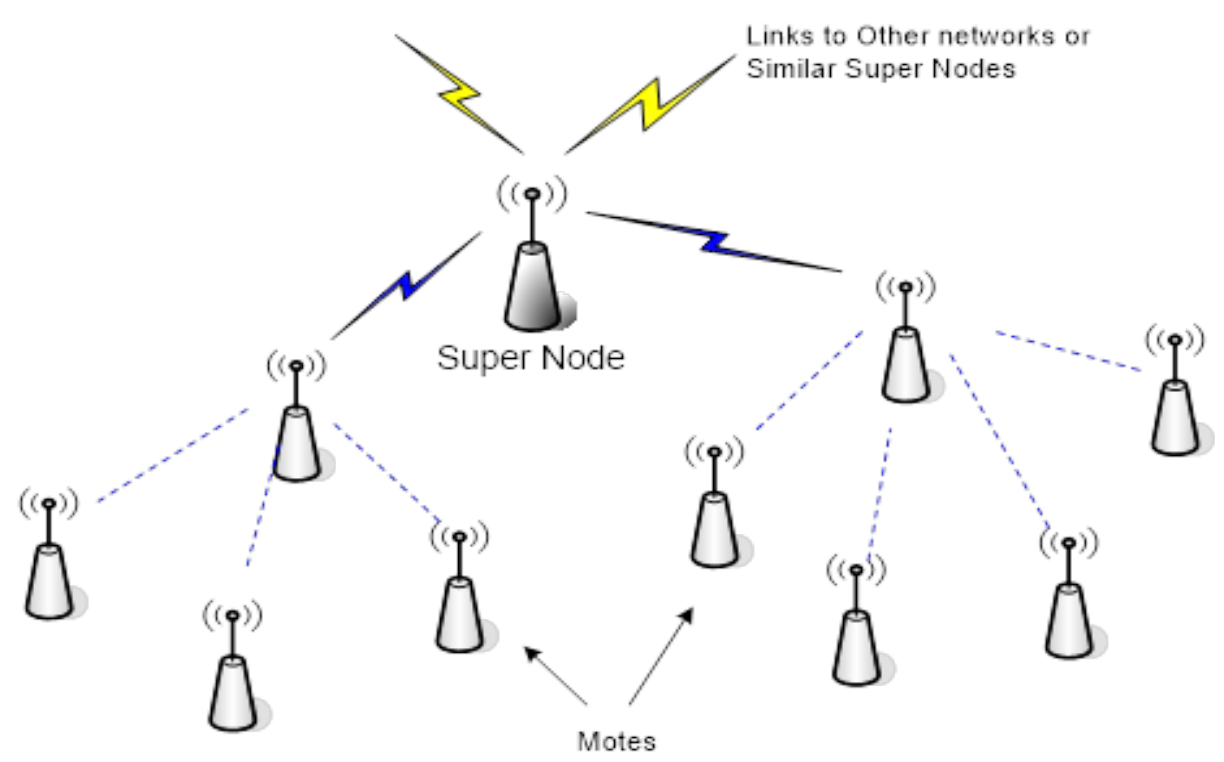

Fig. 2: Prototype of wireless sensor network 
variety of sensors and wireless sensor network. The block diagram of the complete scheme is shown in Figure1. Prototype of wireless sensor network creates by number of motes as shown in Figure2.

\section{Experimental results based on ANSYS}

A virtual underground mine model was set up with following specification to perform the experiment on ANSYS software :Length $=1000 \mathrm{~m}$ Width $=10 \mathrm{~m}$ Height $=10 \mathrm{~m}$ Area $=10000 \mathrm{sqm}$ Two pillars in the middle.

The colour bar indicates the intensity of pressure, density, velocity according to wave length of different coloursie it follows VIBGYOR. Violet has the lowest intensity and red is the highest intensity. The other colour codes lies between them.

\section{RESULTS}

\section{Discussion}

Figure 3a, Figure 3b, Figure 3c, Figure 3d shows different parameters of air quality analysis based on ANSYS. The velocity, density and pressure gradient at normal condition in a underground mines
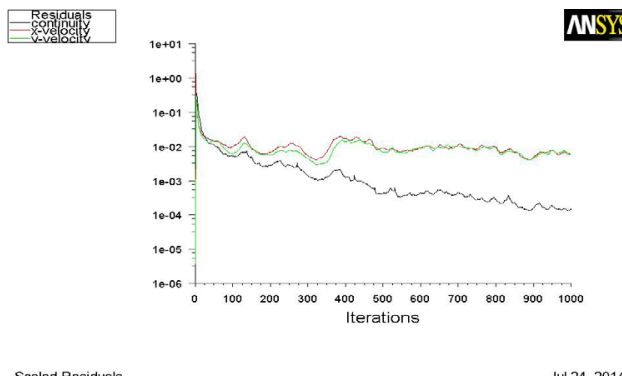

Fig. 3a: Iteration during ANSYS analysis

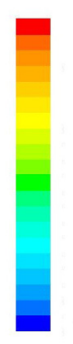

MWYS

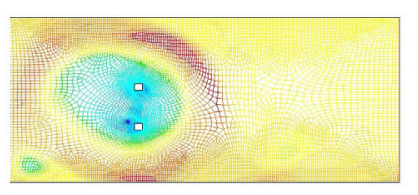

Contours of Total Pressure (pascal)

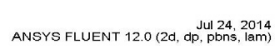

Fig. 3c: Pressure analysis of normal air shown in the above figures. Any fluctuations from the above at any time, during monitoring indicate abnormality in the surrounding environment.

\section{Discussion}

Figure 4a, Figure 4b, Figure 4c, Figure $4 \mathrm{~d}$ shows different parameters of carbon mono oxide gas. Based on these analysis on ANSYS the sensor to find the concentration of carbon mono oxide gas should be installed to that location where the probability of concentration of carbon mono oxide gas is high. We also can deliver information to the underground mine personal about different parameters of this toxic gas like pressure, velocity.

\section{Discussion}

Figure $5 a$, Figure $5 b$, Figure $5 c$, Figure $5 d$ shows different parameters of carbon di oxide gas. Based on these analysis on ANSYS the sensor to find the concentration of carbon di oxide gas should be installed at that location where the probability of concentration of carbon di oxide gas is high. We also can deliver information to the underground mine personal about different parameters of this toxic gas like pressure, velocity.

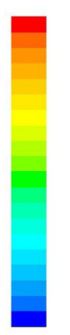

Fig. 3b: Density analysis of normal air

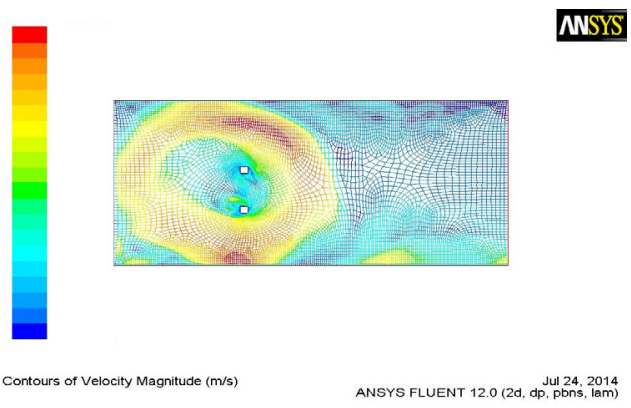

Fig. 3d: Velocity analysis of normal air 

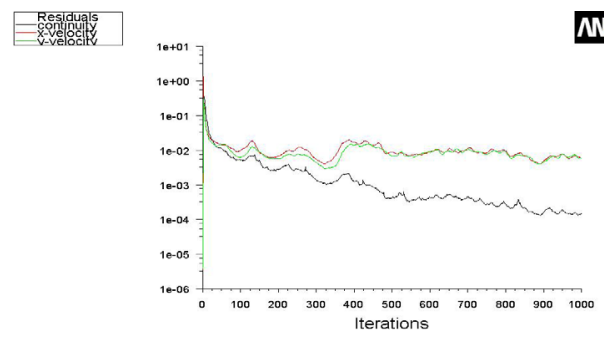

Scaled Residuals

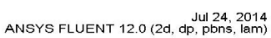

Fig. 4a: Iteration during ANSYS analysis

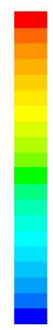

MSYS

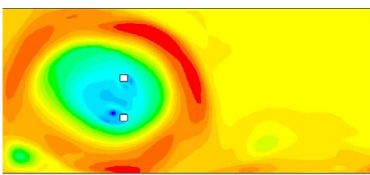

Contours of Total Pressure (pascal)

ANSYS FLUENT 12.0 (2d, JPD, POns, 24014

Fig. 4c: Pressure analysis of normal carbon mono oxide gas

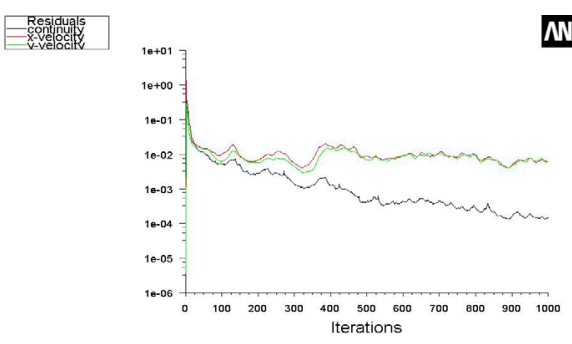

ANSYS FLUENT 12.0 (2d, dp. PDil 24,2014

Fig. 5a: Iteration during ANSYS analysis
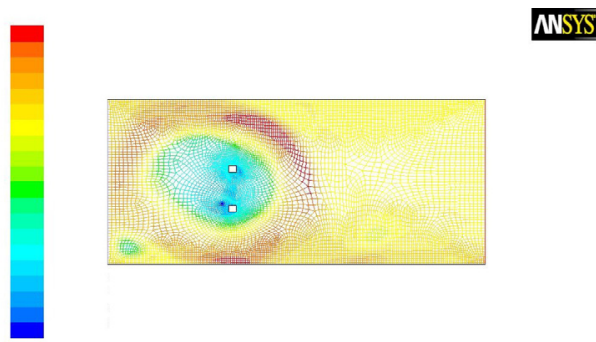

Contours of Total Pressure (pascal)

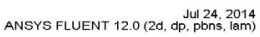

Fig. $5 d$ : Velocity analysis of normal carbon di oxide gas

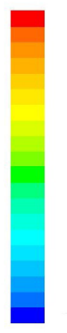

MSYS

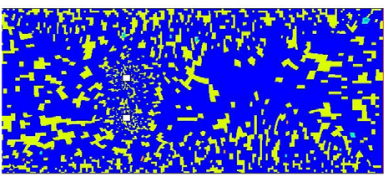

ANSYS FLUENT 12.0 (2d, dpl, pons, 2014

Fig. 4b: Density analysis of normal carbon mono oxide gas

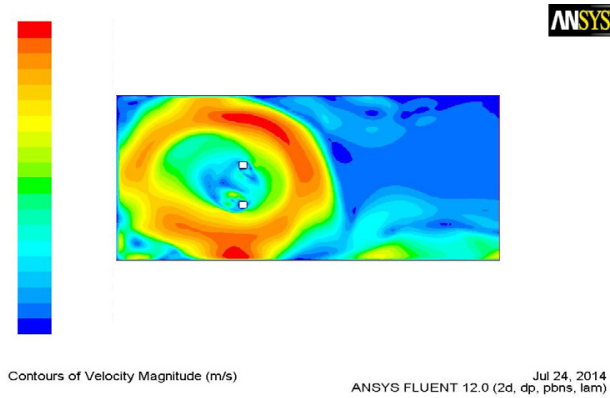

Fig. 4d: Velocity analysis of normal carbon mono oxide gas

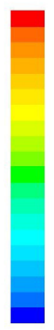

MSYS

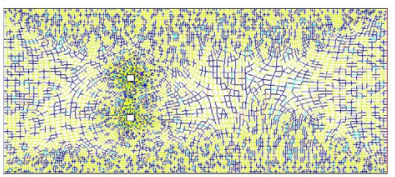

ANSYS FLUENT 12.0 (2d, dp, pDon 24,2014

Fig. 5b: Density analysis of normal carbon dioxide gas

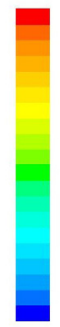

WNSYS

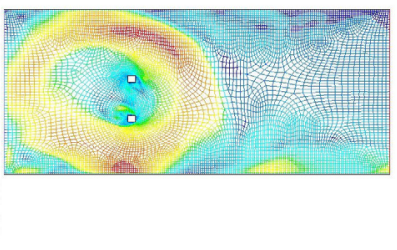

Contours of Velocity Magnitude (m/s)

ANSYS FLUENT 12.0 (2d, dp, pbol 24,2014

Fig. 5c: Pressure analysis of normal carbon di oxide gas 

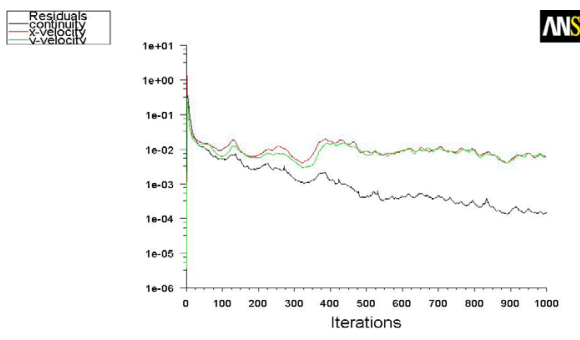

Scaled Residuals

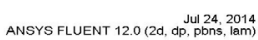

Fig. 6a: Iteration during ANSYS analysis
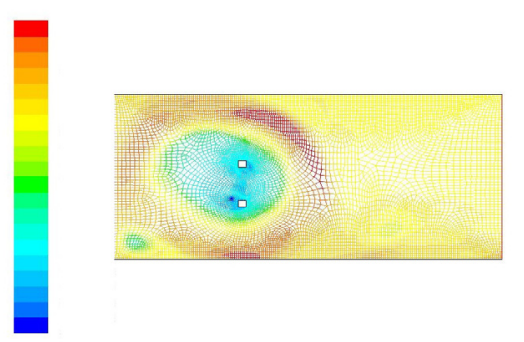

MNSYS

Contours of Total Pressure (pascal)

ANSYS FLUENT 12.0 (2d, dp, pbril 25,2014

Fig. 6c: Pressure analysis of normal hydrogen sulfide gas

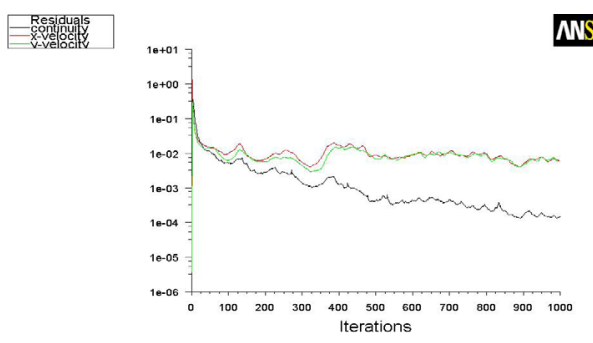

Scaled Residuals

ANSYS FLUENT 12.0 (2d, dp, plol 24.2014

Fig. 7a: Iteration during ANSYS analysis

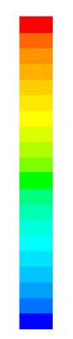

MNYS

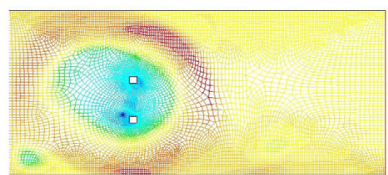

Contours of Total Pressure (pascal)

ANSYS FLUENT 12.0 (2d, Ad Jul PDrs. 2014

Fig. 7c: Pressure analysis of normal Methane gas

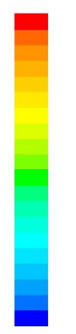

WSYS

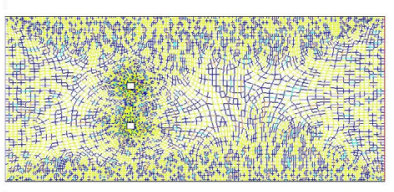

Contours of Density $(\mathrm{kg} / \mathrm{m} 3)$

ANSYS FLUENT 12.0 (2d, dp , plul 25,2014

Fig. 6b: Density analysis of normal hydrogen

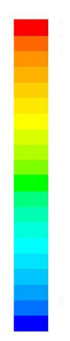

MSSYS

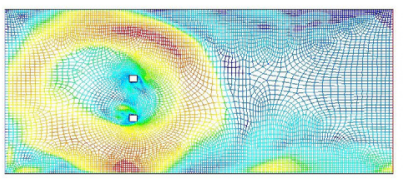

Jul 25, 2014

Fig. 6d: Velocity analysis of normal hydrogen sulfide gas

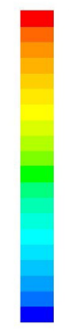

MNSYS

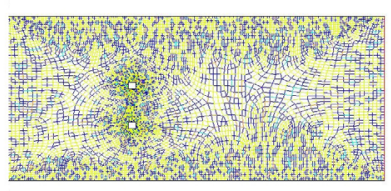

Contours of Density $(\mathrm{kg} / \mathrm{m} 3)$

ANSYS FLUENT 12.0 (2d, dp, pul 25,2014

Fig. 7b: Density analysis of normal Methane gas

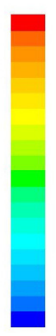

MWYS

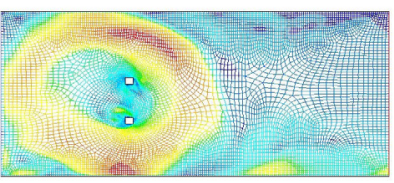

ANSYS FLUENT 12.0 (2d, dp, pbro, 25,2014

Fig. 7d: Velocity analysis of normal Methane gas 


\section{Discussion}

Figure 6a, Figure6b,Figure6c, Figure6d shows different parameters of hydrogen sulfide gas. Based on these analysis on ANSYS the sensor to find the concentration of hydrogen sulfide gas should be installed at that location where the probability of concentration of hydrogen sulfide gas is high. We also can deliver information to the underground mine personal about different parameters of this toxic gas like pressure, velocity.

\section{Discussion}

Figure 7a, Figure 7b, Figure 7c, Figure 7d shows different parameters of Methane gas. Based on these analysis on ANSYS the sensor to find the concentration of Methane gas should be installed to that location where the probability of concentration of Methane gas is high. We also can deliver information to the underground mine personal about different parameters of this toxic gas like pressure, velocity.

\section{Discussion}

Figure $8 \mathrm{a}$, Figure $8 \mathrm{~b}$, Figure $8 \mathrm{c}$, Figure $8 \mathrm{~d}$ shows different parameters of sulphar di oxide gas. Based on these analysis on ANSYS, the sensor to

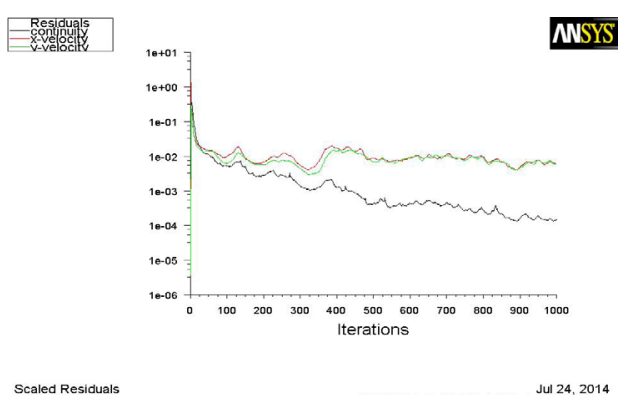

Fig. 8a: Iteration during ANSYS analysis

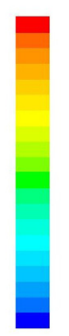

MNSYS

Contours of Total Pressure (pascal)

ANSYS FLUENT 12.0 (2d, dp, pbrs, 25,2014

Fig. 8c: Pressure analysis of normal Methane gas find the concentration of sulphar di oxide gas should be installed at that location where the probability of concentration of sulphar di oxide gas is high. We also can deliver information to the underground mine personal about different parameters of this toxic gas like pressure, velocity.

\section{Total discussion on experimental results based on ANSYS}

The total discussion about different gases helps us to establish a wireless sensor network based system in underground mines. The placement of different sensors is not random. The placement of different sensors is based on analysis of different useful parameters of different gases with the help of ANSYS. The proposed Zigbee based system is cost effective, power saver. The sensor, Zigbee combination module can be preferably installed over the helmet of the personals working in the premises of underground mines. Appropriate monitoring and exchange of facts is achievable among the personals working in the underground environment and the ground staff sitting in the control room, can help to take proper measures further quickly and neatly. The total scheme furthermore can be effortlessly
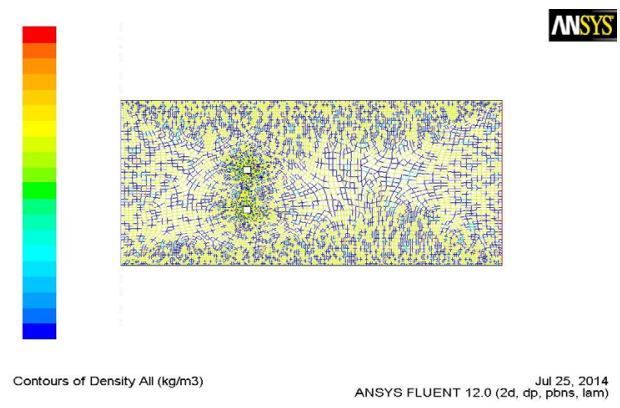

Fig. 8b: Density analysis of normal Methane gas
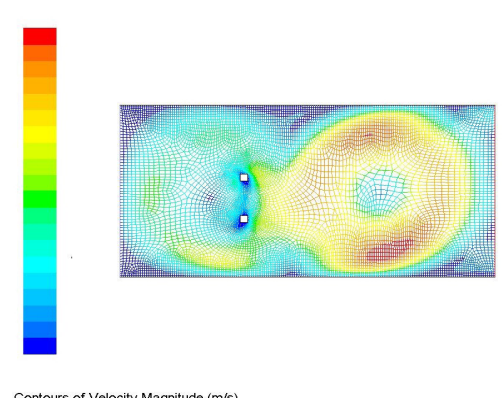

Contours of Velocity Magnitude (m/s)

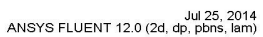

Fig. 8d: Velocity analysis of normal Methane gas 
extended by means of ZigBee wireless image transmission facility in future; it will develop scalability of underground environment, helps us to locate accurate position of underground mine personal.

\section{ACKNOWLEDGMENT}

This work is financially supported by the Indian School of Mines, Dhanbad, India under the Faculty Research Scheme, 2011.

\section{REFERENCES}

1. U.M.Lanjewar, J.Shah J. Air Pollution Monitoring \& Tracking System Using Mobile Sensors and Analysis of Data Using Data Mining. International Journal of Advanced Computer Research. 2(6):19-23 (2012).

2. Chehri A, Fortier P, Tardif PM, editors. Security Monitoring Using Wireless Sensor Networks. Communication Networks and Services Research, 2007 CNSR '07 Fifth Annual Conference on; 2007 14-17 May 2007.

3. Zhangliang $\mathrm{C}$, Liqiang $\mathrm{M}$, Yufeng $\mathrm{S}$, editors. Behavioral Approaches to Safety Management in Underground Mines. Information Technology, Computer Engineering and Management Sciences (ICM), 2011 International Conference on; 2011 24-25 Sept. 2011.

4. Pinto RRaNJ. Using Electro spinning for the Fabrication of Rapid Response Gas Sensors Based on Conducting Polymer Nanowires. IEEE Sensors Journal. 8(6):951-3 (2008).

5. Yingsong $H$, Jingjing $J$, Dan $L$, editors. 3D Simulation of Leakage and Diffusion of Gas in Complex and Sealed Space. Intelligent Computation Technology and Automation (ICICTA), 2011 International Conference on; 2011 28-29 March 2011.

6. Ghosh SK, Chakraborty S, Jamthe A, Agrawal $D P$, editors. Comprehensive monitoring of firefighters by a Wireless Body Area Sensor Network. Wireless and Optical Communications Networks (WOCN), 2013 Tenth International Conference on; 201326 28 July 2013.

7. Mandayo GG, Castano E, Gracia FJ. Carbon monoxide detector fabricated on the basis of a tin oxide novel doping method. Sensors Journal, IEEE. (4):322-8 (2002). doi: 10.1109/jsen.2002.804360.
8. JinSung B, Boungju J, Junyoung N, Youngil K, Sehyun P. An intelligent self-adjusting sensor for smart home services based on ZigBee communications. Consumer Electronics, IEEE Transactions on. 58(3):794-802 (2012). doi: 10.1109/tce.2012.6311320.

9. Kodali RK, editor. Experimental analysis of an event tracking energy-efficient WSN. Advances in Computing, Communications and Informatics (ICACCI), 2013 International Conference on; 2013 22-25 Aug. 2013.

10. Farjow W, Daoud M, Fernando XN, editors. Advanced diagnostic system with ventilation on demand for underground mines. Sarnoff Symposium, 2011 34th IEEE; 2011 3-4 May 2011.

11. Meng-Shiuan P, Chia-Hung T, Yu-Chee T. The Orphan Problem in ZigBee Wireless Networks. Mobile Computing, IEEE Transactions on. 8(11):1573-84 (2009). doi: 10.1109/ tmc.2009.60.

12. Misra P, Kanhere S, Ostry D, Sanjay J. Safety assurance and rescue communication systems in high-stress environments: A mining case study. Communications Magazine, IEEE. 48(4):66-73 (2010). doi: 10.1109/ mcom.2010.5439078.

13. Zhang $X$, editor. Model Design of Wireless Sensor Network Based on Scale-Free Network Theory. Wireless Communications, Networking and Mobile Computing, 2009 WiCom '09 5th International Conference on; 2009 24-26 Sept. 2009.

14. Marriwala N, Rathee P, editors. An approach to increase the wireless sensor network lifetime. Information and Communication Technologies (WICT), 2012 World Congress on; 2012 Oct. 30 2012-Nov. 22012. 
15. Chi-Tsun C, Tse CK, Lau FCM. A DelayAware Data Collection Network Structure for Wireless Sensor Networks. Sensors Journal, IEEE. 11(3):699-710 (2011). doi: 10.1109/ jsen.2010.2063020.
16. Cordos E, Ferenczi L, Cadar S, Costiug S, Pitl G, Chintoanu M, editors. Portable Multigas Toximetre for Areas with Danger of Explosion. Automation, Quality and Testing, Robotics, 2006 IEEE International Conference on; 2006 25-28 May 2006. 